\title{
Rapid Virological Response Represents the Highest Prediction Factor of Response to Antiviral Treatment in HCV-Related Chronic Hepatitis: a Multicenter Retrospective Study
}

\author{
Alessandro Federico ${ }^{1, *}$; Mario Masarone ${ }^{2}$; Marco Romano ${ }^{1}$; Marcello Dallio ${ }^{1}$; Valerio \\ Rosato $^{3}$; Marcello Persico ${ }^{2}$ \\ ${ }_{2}^{1}$ Department of Clinical and Experimental Medicine, Division of Hepatogastroenterology, Second University of Naples, Naples, Italy \\ ${ }^{2}$ Department of Internal Medicine and Hepatology, Internal Medicine and Hepatology Unit, University of Salerno, Salerno, Italy \\ ${ }^{3}$ IV Division of Internal Medicine and Hepatology, Second University of Naples, Naples, Italy \\ ${ }^{*}$ Corresponding Author: Alessandro Federico, Department of Clinical and Experimental Medicine, Division of Hepatogastroenterology, Second University of Naples, Naples, \\ Italy. Tel: +39-0 815666723, Fax:+39-0815666714, E-mail: alessandro.federico@unina2.it
}

Received: February 28, 2014; Revised: May 26, 2014; Accepted: June 22, 2014

\begin{abstract}
Background: Standard [i.e. pegylated interferon (Peg-IFN) + ribavirin] treatment of hepatitis C virus (HCV)-related chronic hepatitis is associated with a sustained virological response(SVR) in 50-90\% of patients. Arapid virological response(RVR)(i.e. negative HCV-RNA after 4 weeks of treatment) predicts SVR in almost $90 \%$ of patients.

Objectives: The main aim of this study was to assess the strength of RVR, as a predictive factor of antiviral treatment response.

Patients and Methods: Using univariate and multivariate analysis, we retrospectively evaluated biochemical, metabolic, genetic and viral variables that might affect both RVR and SVR to Peg-IFN plus ribavirin, in 315 consecutive outpatients affected by HCV-related chronic hepatitis.

Results: At univariate analysis, staging, body mass index, RVR, genotype and viral load were significantly related to SVR $(\mathrm{P}<0.001)$. At multivariate analysis, RVR and genotype remained significant $(\mathrm{P}<0.00001)$. The RVR had a predictive value of $83 \%$. At univariate and multivariate analyses, diabetes $(P=0.003)$, genotype $2(P=0.000)$ and $H C V-R N A$ values $(P=0.016)$ were independent predictors of RVR, even though at multivariate analyses, only genotype 2 was significantly related to RVR. When we stratified patients, according to genotype, no laboratory or clinical factors were predictive of RVR in genotype 1 patients at either univariate or multivariate analysis. In genotype 2 patients, staging $(\mathrm{P}=0.029)$ and diabetes $(\mathrm{P}=0.001)$ were the only significant predictors of RVR at univariate analyses, whereas no factor was independently related to RVR, at multivariate analysis.

Conclusions: The RVR is the strongest factor of SVR and infection with HCV genotype 2 is significantly associated with RVR. Neither biochemical and/or metabolic factors seem to exert influence on RVR.
\end{abstract}

Keywords: Antiviral Agents; Hepatitis C; Pegylated Interferon SA; Retrospective Studies; Ribavirin

\section{Background}

Antiviral therapy for hepatitis C virus (HCV)-related chronic hepatitis results in a post-treatment sustained viral response (SVR) in 50 - 90\% of patients (1). Virus genotype was reported to be the most important predictor of SVR (2). In particular, genotype 1 patients are considered to be 'difficult-to-treat', whereas genotype 2 patients are considered to be 'easy-to-treat' (2). Other genotyperelated factors/cofactors, potentially predictive of SVR, are levels of viremia, virus interference on the genetic background of the host (3), and the host features (genetic background and metabolic interference) (4).

Based on viral kinetics, a decisional algorithm, which identified the 'stopping rules' of therapy, was developed for the follow-up of patients under treatment (5). Patients with an early virological response (EVR) i.e. after 12 weeks of treatment, have a high probability of an SVR and are advised to continue treatment, whereas those who fail to respond after 12 weeks of treatment are asked to discontinue treatment (6). Rapid virological response (RVR), which corresponds to undetectable HCV-RNA after 4 weeks of treatment (7), has been shown to be a robust positive predictor of SVR, and patients infected with HCV genotype 2 or 3 , who achieve RVR, are potential candidates for a short (i.e. 6 months) course of therapy $(8,9)$. While the lack of RVR does not necessarily result in a stopping rule, achieving RVR may serve to motivate patients and has implications, as to the duration of treatment in individual cases. The RVR has a significantly higher predictive value than EVR, and a series of studies, several of which are still ongoing, evaluated whether therapy could be optimized by adjusting the decisional therapeutic algorithm, based on the RVR (10).

Copyright (C) 2015, Kowsar Corp. This is an open-access article distributed under the terms of the Creative Commons Attribution-NonCommercial 4.0 International License (http://creativecommons.org/licenses/by-nc/4.0/) which permits copy and redistribute the material just in noncommercial usages, provided the original work is properly cited. 


\section{Objectives}

This retrospective study, conducted in a series of consecutive patients undergoing antiviral therapy with pegylated interferon (Peg-IFN)- $\alpha 2 \mathrm{a}$ or $-\alpha 2 \mathrm{~b}$ and ribavirin, for HCV-related chronic hepatitis, was designed to evaluate the strength of RVR, as a predictor of SVR, compared to other well-recognized factors/cofactors of response to antiviral therapy, as the primary end-point. A secondary end-point of this study was to also analyze the possible biochemical, metabolic and/or virological interferences on RVR.

\section{Patients and Methods}

We retrospectively studied 315 consecutive outpatients affected by HCV-related chronic hepatitis from January 2009 to September 2011, recruited from three tertiary centers of the Second University of Naples, who were undergoing antiviral therapy with Peg-IFN- $\alpha$ and ribavirin, according to NIH guidelines (11) Epidemiological and clinical characteristics are reported in Table 1 . Inclusion criteria were: 1 ) elevated alanine transaminase (ALT) levels during the last 6 months; 2) HCV antibodies, and 3) no history of alcohol abuse. Exclusion criteria were: 1) overt infection with other hepatitis viruses (i.e. HBsAg+); 3) alcohol abuse (> $20 \mathrm{mg} /$ day in women and $>30 \mathrm{mg} /$ day in men, in the 5 years before enrollment) evaluated according to Reid et al. (12); 4) history of active drug abuse; and 5) HIV-positive test.

\begin{tabular}{|c|c|}
\hline Variables & Values \\
\hline Number of patients & 315 \\
\hline \multicolumn{2}{|l|}{ Gender } \\
\hline Male & 167 \\
\hline Female & 148 \\
\hline Age, $y$ & $52.7 \pm 11.7$ \\
\hline Staging & $2.9 \pm 1.5$ \\
\hline Steatosis & 106 \\
\hline ALT & $68.9 \pm 67.8$ \\
\hline BMI & $26.16 \pm 3.5$ \\
\hline Metabolic syndrome & $63(20)$ \\
\hline Diabetes & $54(17.1)$ \\
\hline Genotype $1 b$ & $217(68.8)$ \\
\hline Genotype 2 & $77(24.4)$ \\
\hline RVR & $136(43.2)$ \\
\hline EVR & $89(28.2)$ \\
\hline SVR & $183(58.1)$ \\
\hline PegIFN a2a & $169(53.6)$ \\
\hline PegIFN a2b & $146(46.4)$ \\
\hline \multicolumn{2}{|c|}{$\begin{array}{l}\text { a Abbreviations: ALT, alanine transaminase; BMI, body mass index; } \\
\text { EVR, early virologic response; PegIFN, pegylated interferon; RVR, rapid } \\
\text { virologic response; SVR, sustained virologic response. } \\
\text { b Data are reported as Mean } \pm \text { SD or No. (\%). }\end{array}$} \\
\hline
\end{tabular}

\subsection{Patient Evaluation}

Virological, epidemiological, biochemical and ultrasound data were recorded upon admission to the centers. Body mass index (BMI) was calculated at the time of liver biopsy. When possible, the apparent disease duration was determined by considering exposure to major risk factors, as infection onset. Diabetes mellitus was identified according to the American Diabetes Association criteria, namely fasting glucose $>126 \mathrm{mg} / \mathrm{dL}$, on two separate occasions, or a positive oral glucose tolerance test, on two separate occasions (13). Total cholesterol, triglycerides, gamma-glutamyl transferase (GGT), ALT and ferritin were measured after a 12-hour fast. Metabolic syndrome was diagnosed according to National Cholesterol Education Program-Adult Treatment Panel III criteria (14). Markers of HBV infection were tested by a commercially available enzyme-linked immunosorbent assay (Abbott Laboratories, Chicago, IL, USA). The study was approved by the Ethics Committee of the Second University of Naples and patients gave their informed consent.

\subsection{Liver Biopsy and Histology}

Hepatic percutaneous biopsy was performed with a Surecut $17 \mathrm{G}$ needle, via the intercostal route, and was echoassisted. Liver specimens were used for histological examination if they were at least $1.5 \mathrm{~cm}$ long and contained more than five portal spaces. Specimens were fixed in formalin, embedded in paraffin, and stained with hematoxylin-eosin. Biopsies were evaluated with the Ishak score (15), and biopsies with steatosis were also scored, according to Brunt's criteria (16).

\subsection{RNA Preparation and Hepatitis C Virus RNA De- termination}

All RNA preparation and HCV RNA determination steps were carried out under RNase-free conditions. We used the polymerase chain reaction (PCR) procedure to determine HCV RNA. Sera were rapidly (within 30 minutes of blood drawing) frozen at $-20^{\circ} \mathrm{C}$. The RNA was extracted according to Chomczynski and Sacchi (17), and c-DNA was derived. We identified HCV RNA using a nested PCR, with primers that expanded the highly conserved 5' non-coding genomic region. Carry-over PCR contamination was avoided by applying the measures suggested by Kwok and Higuchi (18).

\subsection{HCV Genotyping}

To classify HCV genotypes, we hybridized serum PCR products to type- and subtype-specific probes $1 \mathrm{a}, 1 \mathrm{~b}, 2 \mathrm{a}$, $2 \mathrm{~b}$ and $3 \mathrm{a}$. The probes had to fulfill two criteria: no more than two mismatches, compared with the corresponding published sequences of the same subtype, and they had to differ by three or more mismatches, compared with published sequences of other types and subtypes. The only exception is probe $2 \mathrm{~b}$, which had only two mis- 
matches, compared with the corresponding sequence of type $3 a(19)$.

\subsection{Statistical Analysis}

When appropriate, clinical and laboratory data were compared with the Student's t test or the Mann-Whitney test. We used multivariate analysis (logistic regression model) to calculate associations among dependent and independent variables. We used SPSS, ver. 11.5.2.1 for Windows (SPSS Inc., Chicago, IL, USA) to analyze the data. Only $P$ values $<0.05$ were considered significant.

\section{Results}

Independent predictive factors of SVR were identified using univariate analysis in all patients (Table 2). Mul- tivariate analysis was carried out in patients divided according to genotype (Table 3 ). Univariate analysis showed that staging $(\mathrm{P}=0.001)$, BMI $(\mathrm{P}=0.037)$, diabetes $(P=0.000)$, genotype $(P=0.000), R V R(P=0.000)$, and viral load $(P=0.013)$ were significantly associated to SVR (Table 2), whereas at multivariate analysis, only genotype $(\mathrm{P}=0.007)$ and $\mathrm{RVR}(\mathrm{P}=0.000)$ were significantly associated to SVR (Table 3). As shown in Table 3, in genotype-1-infected patients, staging ( $\mathrm{P}=0.018)$, ALT $(\mathrm{P}=0.046)$, metabolic syndrome $(\mathrm{P}=0.041)$, diabetes $(\mathrm{P}=0.009), \operatorname{RVR}(\mathrm{P}=0.000)$ and $\operatorname{EVR}(\mathrm{P}=0.000)$ were significantly associated to SVR, at univariate analysis, while only RVR and EVR $(P=0.000)$ were independently associated to SVR, at multivariate analysis. In genotype 2 patients, only RVR was related to SVR, at both univariate and multivariate analyses.

Table 2. Univariate Analysis vs. Sustained Virologic Response in all Patients and in Genotype $1 \mathrm{~b}$ and $2 \mathrm{a}$

\begin{tabular}{|c|c|c|c|c|c|c|}
\hline \multirow[t]{2}{*}{ Variables } & \multicolumn{2}{|c|}{ All Patients } & \multicolumn{2}{|c|}{ Genotype $1 b$} & \multicolumn{2}{|c|}{ Genotype 2} \\
\hline & OR (95\%CI) & $\mathbf{P}$ & OR(95\%CI) & $\mathbf{P}$ & OR $(95 \% \mathrm{CI})$ & $\mathbf{P}$ \\
\hline Age & $0.742(0.45-1.20)$ & 0.227 & $0.978(0.955-1.003)$ & 0.081 & $0.989(0.947-1.033)$ & 0.626 \\
\hline Sex & $0.821(0.523-1.28)$ & 0.42 & $0.889(0.521-1.516)$ & 0.666 & $0.466(0.149-1.462)$ & 0.184 \\
\hline Staging & $2.49(1.44-4.3)$ & 0.001 & $1.652(1.077-2.533)$ & 0.027 & $0.761(0.499-1.159)$ & 0.203 \\
\hline BMI & $1.8(1.036-3.136)$ & 0.037 & $0.950(0.871-1.037)$ & 0.253 & $0.932(0.766-1.133)$ & 0.479 \\
\hline ALT & $1.001(0.098-1.003$ & 0.6 & $0.995(0.99-1)$ & 0.046 & $0.966(0.989-1.003)$ & 0.39 \\
\hline HOMA & $1.065(0.9-1.25)$ & 0.44 & $1.143(0.931-1.404)$ & 0.201 & $0.901(0.632-1.286)$ & 0.567 \\
\hline MS & $1.54080 .868-2.73)$ & 0.141 & $1.763(1-3.106)$ & 0.041 & $2.380(0.490-11.560)$ & 0.27 \\
\hline Diabetes & $2.996(1.607-5.585)$ & 0.000 & $2.159(1.166-3.995)$ & 0.009 & $0.393(0.102-1.518)$ & 0.165 \\
\hline Steatosis & $0.636(0.397-1.019)$ & 0.060 & $0.603(0.343-1.061)$ & 0.078 & $0.926(0.290-2.954)$ & 0.897 \\
\hline Genotype & $1.575(1.364-1.819)$ & 0.000 & - & - & - & - \\
\hline RVR & $14.87(8.073-27.407)$ & 0.000 & $11.649(5.678-23.896)$ & 0.000 & $11.367(3.174-40.710)$ & 0.000 \\
\hline EVR & $1.628(0.975-2.718)$ & 0.07 & $2.582(1.432-4.657)$ & 0.001 & $0.738(0.210-2.595)$ & 0.635 \\
\hline Peg-IFN $\alpha 2 a$ & $1.870(1.663-1.766)$ & 0.013 & $1.174(0.917-1.503)$ & 0.171 & $1.056(0.244-4.567)$ & 0.947 \\
\hline Peg-IFN $\alpha 2 b$ & $1.058(0.638-1.754)$ & 0.828 & $0.765(0.420-1.391)$ & 0.379 & $0.252(0.031-2.062)$ & 0.169 \\
\hline
\end{tabular}

${ }^{\mathrm{a}}$ Abbreviations:ALT, alanine transaminase; BMI, body mass index; EVR, early virologic response; HOMA, homeostasis model assessment; MS, metabolic syndrome; Peg-IFN, pegylated interferon; RVR, rapid virologic response.

Table 3. Multivariate Analysis vs. Sustained Virologic Response in all Patients and in Genotype $1 \mathrm{~b}$ and $2^{\mathrm{a}}$

\begin{tabular}{|c|c|c|c|c|c|c|}
\hline \multirow[t]{2}{*}{ Variables } & \multicolumn{2}{|c|}{ All Patients } & \multicolumn{2}{|l|}{ Genotype $1 b$} & \multicolumn{2}{|l|}{ Genotype 2} \\
\hline & OR $(95 \% \mathrm{CI})$ & $\mathbf{P}$ & OR $(95 \% \mathrm{CI})$ & $\mathbf{P}$ & OR $(95 \% C I)$ & $\mathbf{P}$ \\
\hline Staging & $0.832(0.639-1.084)$ & 0.173 & $0.953(0.721-1.259)$ & 0.733 & $1.133(0.545-2.356)$ & 0.738 \\
\hline BMI & $0.663(0.273-1.605)$ & 0.362 & - & - & - & - \\
\hline ALT & - & - & $0.998(0.991-1.005)$ & 0.635 & $1.013(0.987-1.040)$ & 0.318 \\
\hline MS & - & - & $1.234(0.260-5.866)$ & 0.792 & $1.930(0.114-32.616)$ & 0.648 \\
\hline Diabetes & $0.481(0.161-1.443)$ & 0.192 & $0.490(0.082-2.915)$ & 0.433 & $0.670(0.033-13.812)$ & 0.670 \\
\hline Genotype & $0.222(0.075-0.660)$ & 0.007 & - & - & - & - \\
\hline RVR & $11.057(4.326-28.265)$ & 0.000 & $78.734(15.346-403.944)$ & 0.000 & $61.159(3.876-964.911)$ & 0.003 \\
\hline EVR & - & - & $25.789(5.347-124.377)$ & 0.000 & $11.678(0.973-140.172)$ & 0.053 \\
\hline
\end{tabular}

a Abbreviations: ALT, alanine transaminase; BMI, body mass index; EVR, early virologic response; MS, metabolic syndrome; RVR, rapid virologic response. 
Federico A et al.

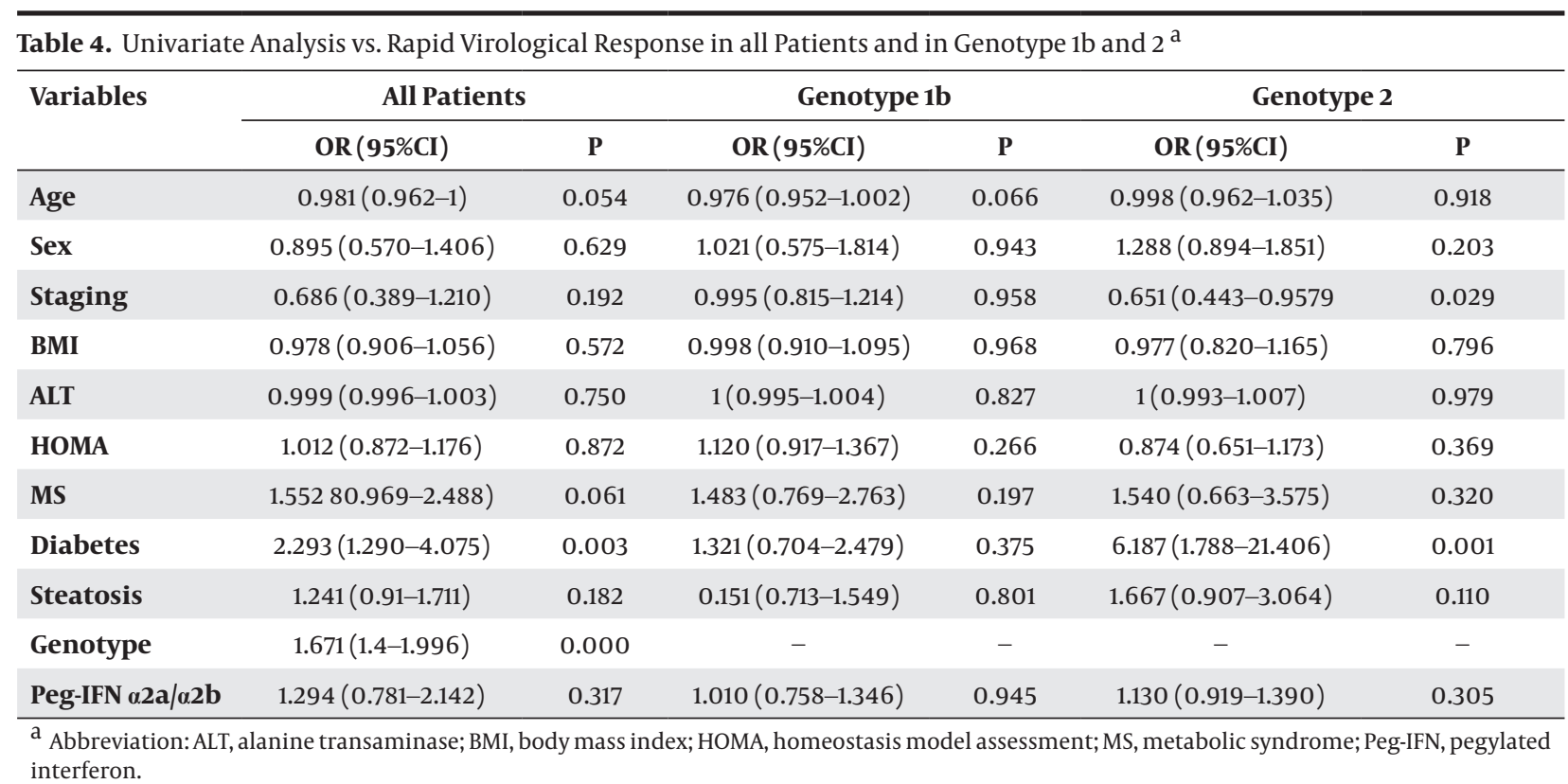

\begin{tabular}{|c|c|c|c|c|c|c|}
\hline \multirow[t]{2}{*}{ Variables } & \multicolumn{2}{|c|}{ All Patients } & \multicolumn{2}{|l|}{ Genotype 1} & \multicolumn{2}{|l|}{ Genotype 2} \\
\hline & OR & $\mathbf{P}$ & OR & $\mathbf{P}$ & OR & $\mathbf{P}$ \\
\hline Age & $0.987(0.964-1.001)$ & 0.294 & $0.950(0.914-0.988)$ & 0.011 & $1.040(0.981-1.103) 574-4.963)$ & 0.186 \\
\hline Staging & & & $1.272(0.968-1.671)$ & 0.085 & $0.594(0.328-1.074)$ & 0.085 \\
\hline MS & $0.862(0.390-1.906)$ & 0.713 & & & & \\
\hline Diabetes & $0.469(0.192-1.143)$ & 0.096 & $0.550(0.208-1.458)$ & 0.230 & $0.149(0.018-1.253)$ & 0.080 \\
\hline Genotype & $0.208(0.114-0.383)$ & 0.000 & - & - & - & - \\
\hline
\end{tabular}

\footnotetext{
a Abbreviations: MS, metabolic syndrome.
}

Tables 4 and 5 show the results of univariate and multivariate analyses of factors predictive of RVR in all patients and in patients divided according to genotype, respectively. Diabetes $(\mathrm{P}=0.003)$, genotype $2(\mathrm{P}=$ $0.000)$ and HCV-RNA $(\mathrm{P}=0.016)$ were significantly related to RVR at univariate analysis, whereas at multivariate analysis, only genotype $2(\mathrm{P}=0.000)$ was an independent predictor of RVR, in all patients. On the other hand, no laboratory or clinical factors were predictive of RVR in genotype $1 \mathrm{~b}$ patients, at either univariate or multivariate analysis. In genotype 2 patients, staging ( $P$ $=0.029)$ and diabetes $(P=0.001)$ were the only significant predictors of RVR, at univariate analyses, whereas no factor was independently related to RVR, at multivariate analysis.

Finally, we evaluated the predictive positive value of EVR and RVR in all patients and in patients according to virus genotype. The predictive positive value (PPV) of SVR was significantly higher in RVR patients, in both genotype groups. In particular, the PPVs of RVR and EVR for SVR were $88 \%$ and $65 \%$, in all patients, respectively. Moreover, PPVs of RVR and EVR for SVR in genotype 1 b patients were $82 \%$ and
$62 \%$, respectively and, in genotype 1 patients, $93 \%$ and $80 \%$, respectively.

\section{Discussion}

In recent years, various attempts have been made to maximize the therapeutic response to antiviral therapy with Peg-IFN and ribavirin in patients with HCV-related chronic hepatitis. Besides dosing adjustments and patient adherence to interferon and ribavirin, tailoring the treatment regimen to the individuality of patients could greatly improve the response to therapy, avoiding relapse and minimizing adverse events. A recent study, in which therapy was optimized according to the patient's baseline characteristics and response to therapy, revealed that RVR is a predictor of SVR, and that duration of treatment could be modulated in relation to this parameter (20).

Factors associated with SVR are either pretreatment or fixed factors (genotype, HCV-RNA levels, histology, race, steatosis, adherence to therapy, etc.) or dynamic factors (RVR and EVR). A SVR probably depends on multiple fac- 
Federico A et al.

tors, and hence, can differ among individuals $(21,22)$. This large multicenter retrospective, consecutive study evaluated the predictive value of RVR for SVR, in both difficultto-treat and easy-to-treat patients. We also assessed the predictive role of a number of parameters, as to RVR. It is noteworthy that our data were obtained in clinical practice and in patients undergoing antiviral therapy with Peg-IFN $\alpha$ and ribavirin, according to NIH guidelines (11), treated with the standard of care for patients with HCVrelated chronic hepatitis.

We found that RVR was the strongest predictor of SVR in all of our patients infected with hepatitis $C$ virus, although there were substantial differences between the two genotypes. In fact, we found that RVR was the only independent factor associated with SVR in overall (i.e. easy-to-treat and difficult-to-treat) patients, whereas in difficult-to-treat patients, both RVR and EVR were independently related to SVR. This result suggests that patients who obtain RVR are likely to have an SVR, irrespective of sex, age, fibrosis and comorbidity. Furthermore, in patients with genotype 1, EVR was related to SVR also, and this finding has implications for treatment duration. It is well known that exposure to IFN and ribavirin, when HCV-RNA is negative, increases the possibility of maintaining the response and of obtaining an SVR. Therefore, an extension of treatment may be beneficial in patients who achieve an $\operatorname{EVR}(23,24)$.

We also found that the patients' metabolic status may affect the likelihood of achieving an RVR. In fact, diabetes was independently related to RVR in all patients, and in patients with genotype 2 , in particular. Therefore, all genotype 2 patients without comorbidity achieved an RVR. On the other hand, in patients with genotype 1, no variable was directly related to RVR at univariate and multivariate analyses. We hypothesize that genotype 1 , per se, influences the metabolic status of patients (25). In conclusion, our study suggests that the occurrence of RVR provides information about treatment outcome in HCVinfected patients. In particular, RVR is confirmed to be the strongest predictor of SVR. Nowadays, triple therapy with protease inhibitors (26) and results from interferonfree trials (27) represent a real option, as a rescue therapy, for those patients who fail to clear the virus after 4 weeks of treatment with Peg-IFN $\alpha$ and ribavirin.

\section{Acknowledgements}

Alessandro Federico, Mario Masarone, Marco Romano, Marcello Dallio, Valerio Rosato: study design, and drafting of the manuscript; Marcello Persico: critical review of the manuscript. All authors were involved in writing the paper and had final approval of the submitted and published versions.

\section{References}

1. Lauer GM, Walker BD. Hepatitis C virus infection. $N$ Engl J Med. 2001;345(1):41-52.
2. Koike K. Antiviral treatment of hepatitis C: present status and future prospects. J Infect Chemother. 2006;12(5):227-32.

3. Mangia A, Gentile R, Cascavilla I, Margaglione M, Villani MR, Stella F, et al. HLA class II favors clearance of HCV infection and progression of the chronic liver damage. J Hepatol.1999;30(6):984-9.

4. Del Campo JA, Romero-Gomez M. Steatosis and insulin resistance in hepatitis C: a way out for the virus? World J Gastroenterol. 2009;15(40):5014-9.

5. Fried MW, Shiffman ML, Reddy KR, Smith C, Marinos G, Goncales FJ, et al. Peginterferon alfa-2a plus ribavirin for chronic hepatitis C virus infection. N Engl J Med. 2002;347(13):975-82.

6. Zeuzem S, Buti M, Ferenci P, Sperl J, Horsmans Y, Cianciara J, et al. Efficacy of 24 weeks treatment with peginterferon alfa-2b plus ribavirin in patients with chronic hepatitis $\mathrm{C}$ infected with genotype 1 and low pretreatment viremia. JHepatol. 2006;44(1):97-103.

7. Kau A, Vermehren J, Sarrazin C. Treatment predictors of a sustained virologic response in hepatitis B and C. J Hepatol. 2008;49(4):634-51.

8. Berg T, Carosi G. Optimizing outcomes in patients with hepatitis C virus genotype 2 or 3. Antivir Ther. 2008;13 Suppl 1:17-22.

9. Lee SS, Ferenci P. Optimizing outcomes in patients with hepatitis C virus genotype 1 or 4. Antivir Ther. 2008;13 Suppl 1:9-16.

10. Hadziyannis SJ, Sette HJ, Morgan TR, Balan V, Diago M, Marcellin $\mathrm{P}$, et al. Peginterferon-alpha2a and ribavirin combination therapy in chronic hepatitis C: a randomized study of treatment duration and ribavirin dose. Ann Intern Med. 2004;140(5):346-55.

11. National Institutes of $\mathrm{H}$. National Institutes of Health Consensus Development Conference Statement: Management of hepatitis C: 2002-June 10-12, 2002. Hepatology. 2002;36(5 Suppl 1):S3-20.

12. Reid MC, Guo Z, Van Ness PH, O'Connor PG, Concato J. Are commonly ordered lab tests useful screens for alcohol disorders in older male veterans receiving primary care\&\#63. Subst Abus. 2005;26(2):25-32.

13. American Diabetes A. Diagnosis and classification of diabetes mellitus. Diabetes Care. 2006;29 Suppl 1:S43-8.

14. Grundy SM, Cleeman JI, Daniels SR, Donato KA, Eckel RH, Franklin BA, et al. Diagnosis and management of the metabolic syndrome: an American Heart Association/National Heart, Lung, and Blood Institute Scientific Statement. Circulation. 2005; 112(17):2735-52.

15. Ishak K, Baptista A, Bianchi L, Callea F, De Groote J, Gudat F, et al. Histological grading and staging of chronic hepatitis. J Hepatol. 1995;22(6):696-9.

16. BruntEM. Nonalcoholic steatohepatitis. Semin LiverDis. 2004;24(1):3-20.

17. Chomczynski P, Sacchi N. Single-step method of RNA isolation by acid guanidinium thiocyanate-phenol-chloroform extraction. Anal Biochem. 1987;162(1):156-9.

18. Kwok S, Higuchi R. Avoiding false positives with PCR. Nature. 1989;339(6221):237-8.

19. Viazov S, Zibert A, Ramakrishnan K, Widell A, Cavicchini A, Schreier E, et al. Typing of hepatitis $C$ virus isolates by DNA enzyme immunoassay. J Virol Methods. 1994;48(1):81-91.

20. Arase Y, Suzuki F, Sezaki H, Suzuki Y, Kawamura Y, Kobayashi M, et al. Suitable treatment period in patients with virological response during combination therapy of peginterferon and ribavirin for chronic hepatitis C. Intern Med. 2008;47(14):1301-7.

21. Zuberi BF, Zuberi FF, Memon SA, Qureshi MH, Ali SZ, Afsar S. Sustained virological response based on rapid virological response in genotype-3 chronic hepatitis $\mathrm{C}$ treated with standard interferon in the Pakistani population. World J Gastroenterol. 2008;14(14):2218-21.

22. Andriulli A, Mangia A, Iacobellis A, Ippolito A, Leandro G, Zeuzem S. Meta-analysis: the outcome of anti-viral therapy in HCV genotype 2 and genotype 3 infected patients with chronic hepatitis. Aliment Pharmacol Ther. 2008;28(4):397-404.

23. Petta S, Craxi A. How to optimize HCV therapy in genotype 1 patients: predictors of response. Liver Int. 2013;33 Suppl 1:23-9.

24. Toyoda H, Kumada T, Shimada N, Takaguchi K, Ide T, Sata M, et al Significance of a reduction in HCV RNA levels at 4 and 12 weeks in patients infected with HCV genotype $1 \mathrm{~b}$ for the prediction of the outcome of combination therapy with peginterferon and ribavirin. BMC Infect Dis. 2012;12:324. 


\section{Federico A et al.}

25. Petta S, Bellia C, Mazzola A, Cabibi D, Camma C, Caruso A, et al Methylenetetrahydrofolate reductase homozygosis and lowdensity lipoproteins in patients with genotype 1 chronic hepatitis C. J Viral Hepat. 2012;19(7):465-72.

26. Petta S, Craxi A. Therapeutic algorithms for chronic hepatitis
$C$ in the DAA era during the current economic crisis: whom to treat? How to treat? When to treat? BMC Infect Dis. 2012;12 Suppl 2:S3.

27. Lange CM, Zeuzem S. Perspectives and challenges of interferonfree therapy for chronic hepatitis C. J Hepatol. 2013;58(3):583-92. 